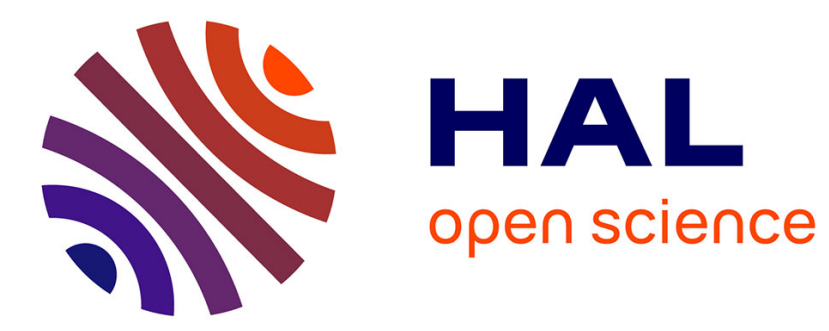

\title{
GaN Power Module with High Temperature Gate Driver and Insulated Power Supply
}

Rémi Perrin, Dominique Bergogne, Christian Martin, Bruno Allard

\section{To cite this version:}

Rémi Perrin, Dominique Bergogne, Christian Martin, Bruno Allard. GaN Power Module with High Temperature Gate Driver and Insulated Power Supply. HITEC 2014, May 2014, Albuquerque, United States. 10.4071/HITEC-WP11 . hal-01191419

\section{HAL Id: hal-01191419 https://hal.science/hal-01191419}

Submitted on 1 Sep 2015

HAL is a multi-disciplinary open access archive for the deposit and dissemination of scientific research documents, whether they are published or not. The documents may come from teaching and research institutions in France or abroad, or from public or private research centers.
L'archive ouverte pluridisciplinaire HAL, est destinée au dépôt et à la diffusion de documents scientifiques de niveau recherche, publiés ou non, émanant des établissements d'enseignement et de recherche français ou étrangers, des laboratoires publics ou privés. 


\title{
GaN Power Module with High Temperature Gate Driver and Insulated Power Supply
}

\author{
Rémi Perrin, Dominique Bergogne, Christian Martin, Bruno Allard \\ INSA de Lyon, F-69622, France \\ CNRS, UMR5005, France, \\ INSA Lyon, Université Claude Bernard Lyon 1 \\ Laboratoire Ampère, batiment L. de Vinci, 21 Av. Jean Capelle \\ F-69621, France \\ remi.perrin@insa-lyon.fr
}

\begin{abstract}
Emerging GaN power switches show advantages for integration in power modules at high temperature and/or high efficiency. These modules are good candidates for embedded power converters in harsh environment such as three phase inverters for Electro-Mechanical Actuators (EMA) in the vicinity of internal combustion engines. The power range is usually within 1 to $5 \mathrm{~kW}$, extending sometimes up to $50 \mathrm{~kW}$, using a high voltage DC bus (HVDC) that is usually comprised between $200 \mathrm{~V}$ and $600 \mathrm{~V}$. For aeronautical applications, GaN power switches could challenge $\mathrm{SiC}$ transistors for their high switching speed, hence reduced switching losses, therefore lower embarked mass. For automotive applications, it is the relative promise for lower cost per Amp that is pushing this technology up. This is why a project joining $\mathrm{GaN}$ device conception, power module development and gate driver optimization using high temperature technologies was set-up. This paper presents the first practical results: a functional GaN power inverter-leg driven by a specific high temperature gate driver with signal and power insulation. This building block requires an auxiliary DC supply with a input voltage of $14 \mathrm{~V}$ or $28 \mathrm{~V}$ and an external PWM control signal. Current rating is $20 \mathrm{~A}$ and breakdown voltage is $200 \mathrm{~V}$.
\end{abstract}

\section{Keywords}

GaN, Dedicated Driver, High-Temperature, Power-Supply.

\section{Introduction}

The trend of electrification in Aerospace applications requires both high temperature and high frequency operation to achieve high power density for the future power converters. This implies that power modules in such converters need to operate at very high ambient temperatures, e.g. $200-250{ }^{\circ} \mathrm{C}$, package parasitics must be as low as possible, switching frequencies are in the $20 \mathrm{kHz}$ to $200 \mathrm{kHz}$ range. Moreover, the $\mathrm{GaN}$ technology has emerged as promising for high frequency, high efficiency and high density power conversion due to a better figure of merit [1-4].than comparable $\mathrm{Si}$ and $\mathrm{SiC}$ transistors. A progressively larger number of GaN devices have been manufactured for a large field of applications from low power voltage regulators to high power infrastructure base-stations. The switching frequency has been continuously increased to reduce passive component size and to increase power density. The work presented in this paper aims to deliver a functional prototype of driver and power supply for a power module implementing normally-on High electron Mobility GaN Transistors (HEMT) in high temperature environment. The normally-on issue of power switches is not dealt with in this paper, previous work on $\mathrm{SiC}$ normally-on transistors have addressed this [5-10].

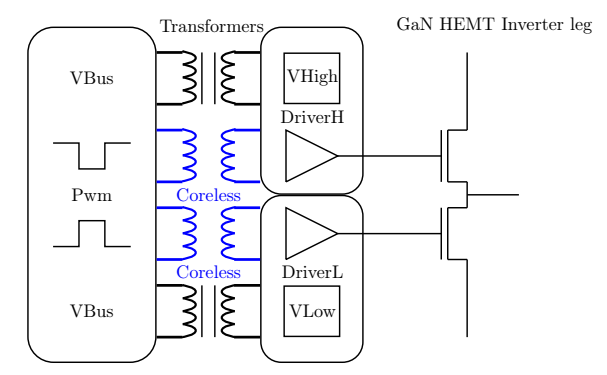

Figure 1: Schematic of a single inverter leg with a highvoltage DC-Input bus including gate drivers and insulation of control signals and power. 


\section{Prototype GaN Module}

The GaN transistors come from the first run of HEMT devices provided by CEA-LETI laboratory, France. These test vehicles have been used to validate the process technique and to push forward experimental work on $\mathrm{GaN}$.

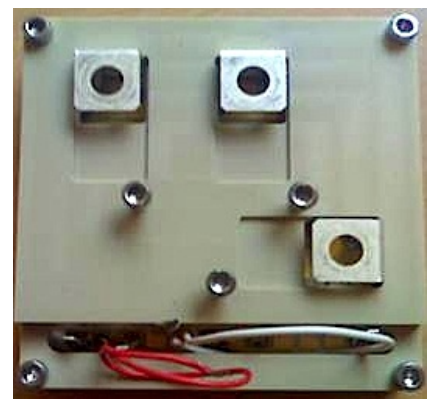

Figure 2: High Temperature GaN inverter leg Power Module. Module property of CEA-LETI.

The Power Inverter Module specifications are summarized in Table 1.

\begin{tabular}{|l|c|}
\hline Item & Parameter \\
\hline Base plate & AlN-Cu \\
Top lid & PEEK \\
Max voltage & $200 \mathrm{~V}$ \\
Rated current & $20 \mathrm{~A}$ \\
Gate charge & $7 \mathrm{nC}$ \\
Gate capacitance & $1 \mathrm{nF}$ \\
Threshold voltage & $-3.2 \mathrm{~V} \mathrm{@} 25^{\circ} \mathrm{C}$ \\
\hline
\end{tabular}

Table 1: Experimental GaN power Module specifications. PEEK stands for PolyEther Ether Ketone

This power module is built with $200 \mathrm{~V}-20 \mathrm{~A}$ - $30 \mathrm{mOhms} \mathrm{GaN} \mathrm{HEMT} \mathrm{from} \mathrm{CEA-LETI} \mathrm{and} 1200 \mathrm{~V}$ - 50 A SiC Schottky diode (ref: 5SLY12E1200-5YA1681-00 from ABB). Direct-bonded-copper technology (DBC) is used and GaN dies are brazed using a $63 \mathrm{Sn} / 37 \mathrm{~Pb}$ alloy.

\subsection{Static characterizations}

The scope of this paper is to provide guidance to design engineers and to assess the progress made on our project. Precise characterization of the HEMT static behavior is not addressed here, one practical reason is that the components used are the firsts to be tested on a program where improvements are made for each run of devices. More, for the power converter designer or the application engineer, power switches are firstly described by their gate threshold voltage,Vth, and by the on-resistance, RdsON, (static parameters), then by their switching speed and losses (dynamic parameters). The threshold voltage is an input for the gate drive circuit and the on-resistance permits to evaluate the voltage drop across the conducting switch, hence calculate the conduction losses. Firstly, the module is characterized under various temperatures up to $200{ }^{\circ} \mathrm{C}$. Figure 3 and figure 4 show the temperaturedependence of static characteristics (Vth and RdsON). During the test, the module's substrate temperature is monitored with an external thermocouple, and is regulated by a hotplate. The test is set so that there is no significant self-heating, so the substrate's temperature is very close to the chip temperature. The threshold

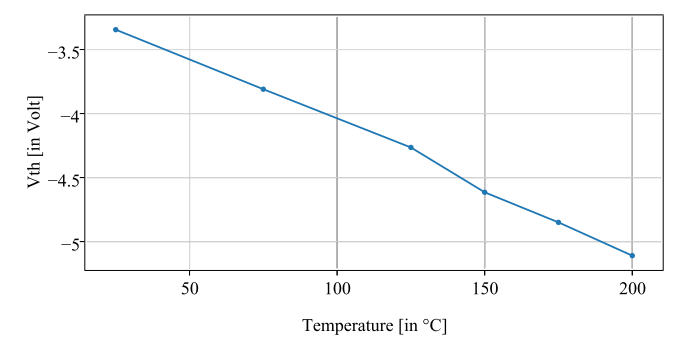

Figure 3: Temperature dependence of the threshold gate voltage of GaN HEMT's.

voltage is determined using two different techniques : first a standard transconductance curve is plotted and the threshold voltage is extracted, secondly, during the inverter leg switching operation, the value of the gate voltage during the transients (also known as the Miller plateau) permits to determine the threshold voltage. Both techniques provided the same values. Finally, the temperature dependency of Vth is plotted in figure 3. On the temperature range, the threshold voltage temperature dependency is almost linear and is $-10 \mathrm{mV} /{ }^{\circ} \mathrm{C}$. The second parameter is the onresistance, it is measured using a $1 \mathrm{~A}$ current pulse and measuring the voltage drop.

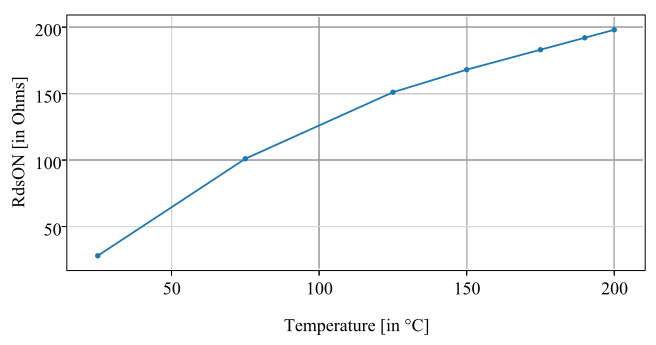

Figure 4: Temperature dependence of the drain to source resistance at null gate voltage and $1 \mathrm{~A}$ drain current. 


\subsection{Switching characterizations}

The switching test provides useful information on the module such as the influence of parasitic elements, switching speed or power losses. However, switching power losses measurements would not be relevant because the Power Module Package was not optimized for switching losses reduction. The internal assembly uses wire bonding and simple metal frame to make the electrical connections, introducing an important stray inductance in the power path that impacts the switching behavior. However, the gate charge specification is a key parameter for the gate driver designer as it sets the power consumption of the gate driver for a given operating frequency. For this test the module is driven by a $-6 \mathrm{~V}$ gate voltage and a 2 Ohms gate resistor. The measured gate voltage turn-On and turn-Off in

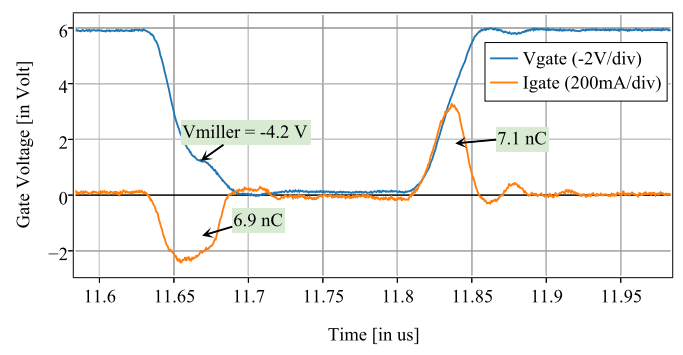

Figure 5: Gate voltage and gate current during turn-on and turn-off states.

figure 5, show the energy necessary to bias the HEMT gate. It is also an experimental technique to determine a mean value of the gate capacitance, a parameter used to design the gate driver. With this HEMT module, the measured mean gate capacitance value is $1 \mathrm{nF}$.

\section{Gate driver for GaN devices}

\subsection{Specifications}

The specifications for the driver are partially set by the gate properties of the $\mathrm{GaN}$ transistors, especially the threshold voltage. The comes power consumption, board space, etc. We have chosen to use commercially available circuits and engineering samples for our project. There are several suppliers of commercial high temperature integrated circuits, one of them is situated near our laboratory, X-Relsemi, http: //www.x-relsemi.com/. The isolated gate driver is implemented with a XTR40011 transceiver and a XTR26011 driver. The baseline driver design implements ferrite cores from Ferroxcube (TC 6/4/2) ensure the data signal insulation. An improvement to increase

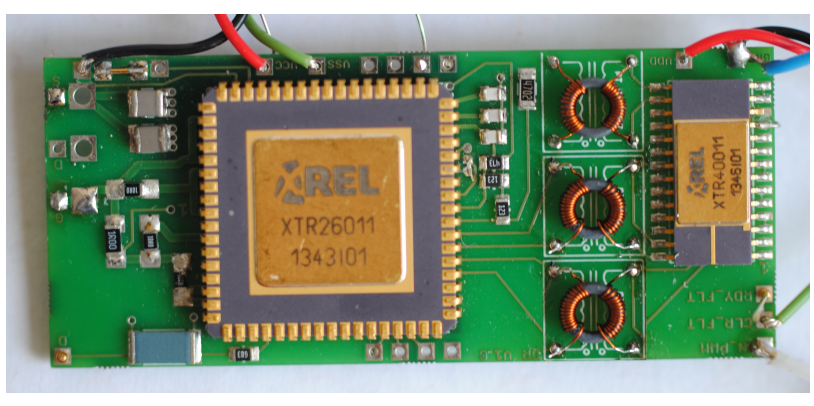

Figure 6: Picture of GaN driver board with 3 magnetic cores for signal insulation compatible with coreless transformers.

the driver density is to replace those cores by coreless transformers, [11].

Characteristics of the driver are summarized in table 2 . The XTR26011 offers the possibility to imple-

\begin{tabular}{|l|c|}
\hline Item & Parameter \\
\hline Technology & SOI \\
Temperature range & $-60^{\circ} \mathrm{C}$ to $+200^{\circ} \mathrm{C}$ \\
Gate driver supply voltage & $6 \mathrm{~V}$ \\
Gate voltage tolerance & $5 \%$ \\
Peak output current & $3 \mathrm{~A}$ \\
Static power consumption & $105 \mathrm{~mW} @ 25^{\circ} \mathrm{C}$ \\
Gate resistor & adjustable \\
Frequency range & up to $300 \mathrm{kHz}$ \\
\hline
\end{tabular}

Table 2: GaN driver board specifications.

ment different protections. The Under-Voltage-LockOut (UVLO) of the driver IC has been set to $-5.5 \mathrm{~V}$, because this is just over to the threshold voltage of the HEMTs at $200^{\circ} \mathrm{C}$. The short-circuit protection, called DESAT, has been adjusted for a drain to source voltage of about $3 \mathrm{~V}$, this value is chosen according to the application and thermal limits. An interesting function specific to $\mathrm{GaN}$ devices is implemented, a gate circuit protection : in case of a gate to source short circuit, the driver decrease the output current and a flag turnsoff. This functionality, coupled with current regulation of the power gate supply, gives a safe system against over-current and overshoot voltage. Nevertheless, the system designer has take into account the failure of the power device, but the gate driver board remains safe.

\subsection{Insulated Power supply}

Flyback converters are used in power supplies requiring low to medium output power at several output voltages. Due to the high costs of high-temperature components, the flyback converter has the advantage to require a low number of components. The main switch is a N-MOSFET (ref : XTR2N0825 from X-Relsemi) and the diodes are SiC diodes (ref : C3D02060E 
from CREE, http://www.cree.com/). The transformer is built using a low permeability nanocrystalline core from APERAM, http://www.aperam. $\mathrm{com} /$ (ref : 095045 B600), a high-temperature enameled copper wire and a high temperature polymer thermoplastic (PEEK) machined housing.

The regulation is based on quasi-regulation techniques by using a third dedicated winding on the transformer [12], this provides the insulation of the feedback regulation circuit at high temperature. The PWM controller (ref : XTR30014) is supplied by X-Relsemi. In order to be in line with industrial applications, an EMI input filter with high-temperature ceramic capacitors from SRT-Céramique, http://www.srt-mc.com/, is used and an input inrush current limiter is implemented.

The power supply specifications are summarized in table 3 .

\begin{tabular}{|l|c|}
\hline Item & Parameter \\
\hline Type & quasi-regulated Flyback \\
Input voltage & $28 \mathrm{~V}$ \\
Output voltage & $2 \mathrm{X} \mathrm{10 \textrm {V }}$ \\
Load regulation & $( \pm 8 \%)$ \\
Current output max & $200 \mathrm{~mA}$ \\
Switching frequency & $200 \mathrm{kHz}$ \\
Insulation prim./sec. & $1.5 \mathrm{KV}$ \\
Temperature range & $-60^{\circ} \mathrm{C}$ to $+200^{\circ} \mathrm{C}$ \\
\hline
\end{tabular}

Table 3: Insulated flyback converter specifications. A linear post regulator will be used to provide a tighter tolerance, lower than $2 \%$.

In figure 7 , the inductance of the input filter and the nanocrystalline transformer (two clear disks on the picture) are the largest components. They are both packaged using PEEK to withstand high temperature operation. Moreover, we use NPO series ceramic capacitor from SRT-Ceramique, http://www.srt-mc.com/, for the input-filter.

Figure 8 shows the output voltage variation and duty-cycle variation vs. current output at ambient temperature. The quasi-regulation of the output voltage reaches less than $\pm 8 \%$ accuracy. We can observe that the PWM controller adjusts correctly the dutycycle ratio for different load change.

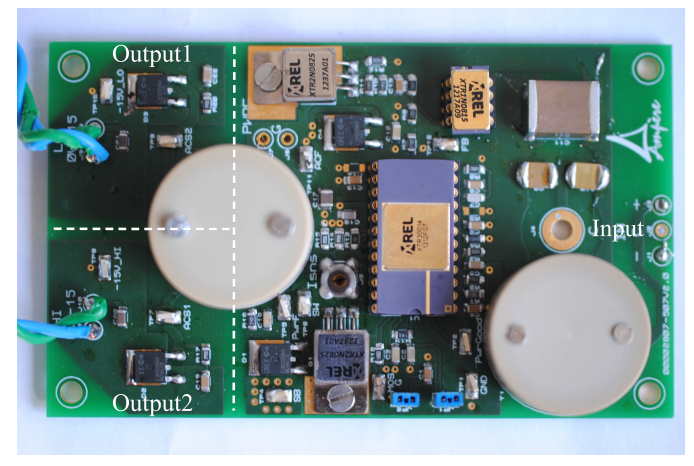

Figure 7: Picture of the Insulated Flyback power supply with two quasi-regulated outputs. A post linear regulator is used, but it is not visible on this view.

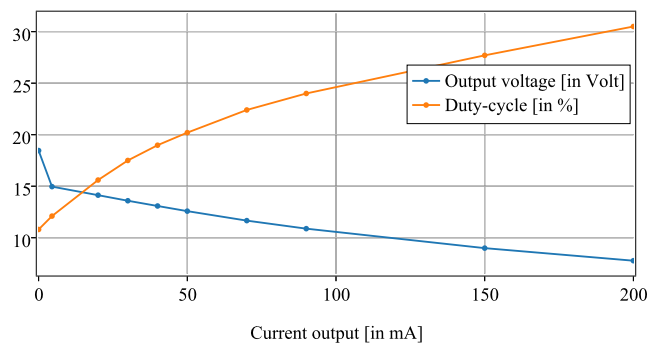

Figure 8: Output voltage and Duty-cycle variation vs. Current output.

In figure 9, a high-temperature test is made at the nominal output current, $(200 \mathrm{~mA})$, up to $200^{\circ} \mathrm{C}$ to plot the flyback output voltage variations. The performance is mainly determined by the PWM controller using the feedback loop. The test on the flyback converter shows an output voltage variation of about $+1.8 \%$ in the temperature range, which is within the specifications for the gate drive.

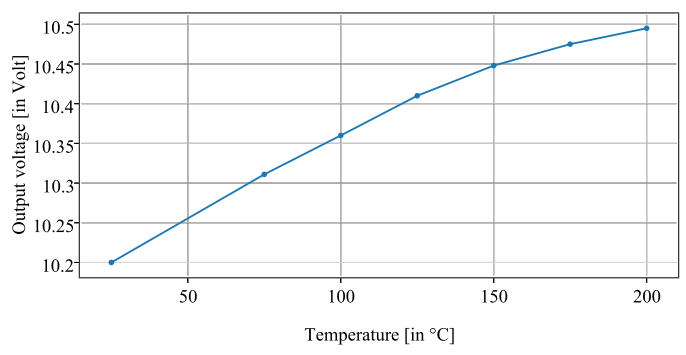

Figure 9: Temperature dependence of the flyback output voltage. 


\subsubsection{Gate Driver Voltage Regulation}

The HEMT gate might be damaged by over-voltages, this is why the tolerance on the gate voltage is set to $5 \%$. The quasi-regulation implemented in the flyback converter has some drawbacks like a poor opal regulation. A post-regulation has been added to improve the voltage stability of the driver supply and to control tightly the gate voltage. A voltage linear regulator is proposed by X-Relsemi (ref. XTR75011) providing a $1 \%$ tolerance. However, the maximum regulated current is $50 \mathrm{~mA}$. So, in order to increase the output current up to the specifications ( $200 \mathrm{~mA}$ ), a common current booster circuit, as depicted in figure 10, is implemented. The principle is simple : a series resistor (R1) is placed at the input of the integrated voltage regulator. As the output current increases, the voltage drop across the resistor increases. This voltage drives an external P-MOSFET (M1) so that, when the gate threshold is reached, the transistor diverts as much current as needed to keep the voltage drop in the series resistor close to the gate threshold voltage. In that way, the voltage regulator integrated circuit (XTR75011) is operated at a constant current and the MOSFET supplies any value of current higher than that constant current. Note that this solution boosts the output current capability of the voltage regulator chip but does not provide any significant extension of the input voltage handling. To reach temperatures up to $200^{\circ} \mathrm{C}$, this transistor must also be a high temperature device. The XTR2N0525, a P-MOSFET from X-Relsemi, has been chosen.

Figure 11 describes the output voltage for an out-

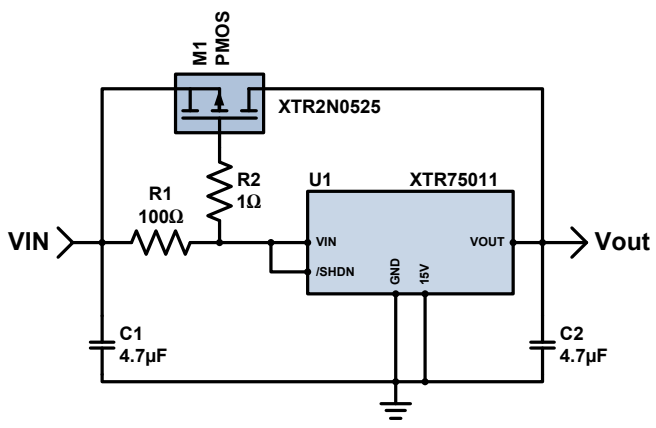

Figure 10: Schematic of current boost regulator (drawing courtesy of X-Relsemi).

put current range of $0 \mathrm{~mA}$ to $800 \mathrm{~mA}$, well over the specified $200 \mathrm{~mA}$. The voltage variation is $0.5 \%$, well within the specifications.

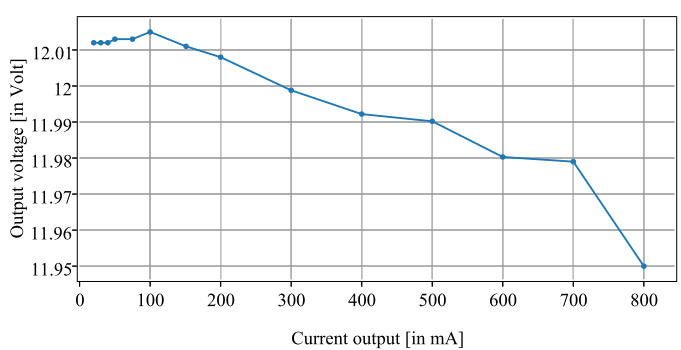

Figure 11: Output voltage drop vs. output current.

Figure 12 represents the effect of temperature on the output voltage. For this test, the current boosted regulator of figure 10 has been heated up to $200^{\circ} \mathrm{C}$, with an input voltage of $16 \mathrm{~V}$ and an output current set at $200 \mathrm{~mA}$. Temperature has little effect on the precision which is close to $0.5 \%$, well within the specifications.

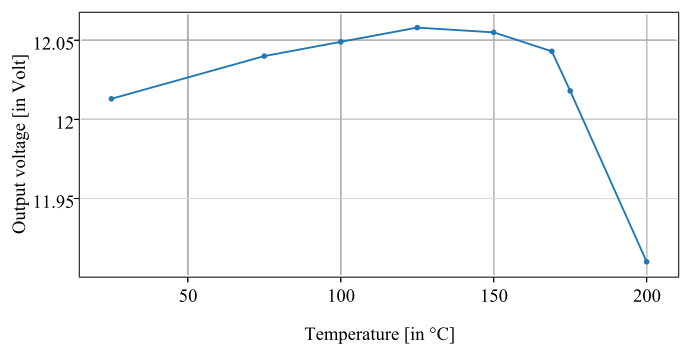

Figure 12: Output voltage variation vs. Temperature.

To conclude with, the post-regulation proposed in this section permits to reach the gate driver supply specifications up to $200^{\circ} \mathrm{C}$.

\subsection{Insulation of control signals}

Control signals sets the power module switches's states. This on/off digital signal comes from some sort of controller, at low voltages and has to be converted and applied to the gates of the power switches. In an inverter leg, such as the one implemented in the module, insulation is mandatory due to high voltages and separated voltage references. Engineers and scientists have produced a huge variety of solutions ranging from transformers to optical links systems. Recent advances have brought to industrial levels the coreless technology for the insulation of control signals in an integrated driver chip. However, there is an interest in developing a discrete coreless transformer, especially to extend the temperature range above $175^{\circ} \mathrm{C}$. 


\subsubsection{Coreless technology}

Coreless transformers are processed using Integrated Passive Device technology (IPD) from STMicroelectronics. It consists of a glass wafer onto which two layers of copper are placed, insulated by a specific resin. It should be noted that the resin is a broad band-sensitive photopolymer named B-staged bisbenzocyclobutene (BCB). It is intended to be used as a dielectric material in thin film microelectronics applications. This polymer was not specially developed for high temperature applications, however the process of reticulation that happens during the initial curing process leads to believe that an extension of the usual temperature limit $\left(125^{\circ} \mathrm{C}\right.$ to $\left.175^{\circ} \mathrm{C}\right)$ is achievable. A preliminary endurance test at $200^{\circ} \mathrm{C}$ is presented further down in this paper. Note that the windings are made of copper and are built using two layers of metal.

The primary winding and the secondary winding are

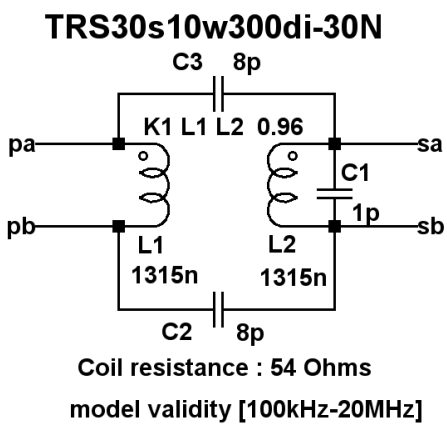

Figure 13: Equivalent model of the coreless transformer.

etched on the same metal level, while the second metal level is used to "bring back" the extremum of the coil from the center of the device to the side of the chip. For some applications it is necessary to have the contact pads at the corner of the chip, for improved insulation in the package for example. This implementation is called "single layer" transformer and is noted "TRS". It was chosen over a double layer structure because the parasitic capacitance is less. In the double layer structure, an additional capacitance is introduced by the coils facing each other to form a planar capacitor. In [13], the authors describe the design of the coreless transformers and describe the equivalent model.

\subsubsection{Signal transmission through coreless trans- formers}

A demo board supplied by X-Relsemi was used to test the coreless transformers. The original Ferroxcube cores are replaced by the coreless transformers. In figure 14 one can observe the input PWM signal, the output of the transceiver modulation, the output of the coreless transformer and finally the demodulated PWM signal. The transmission delay is impacted by the modulation/demodulation technique. The experimental date gives a mean delay od $300 \mathrm{~ns}$.

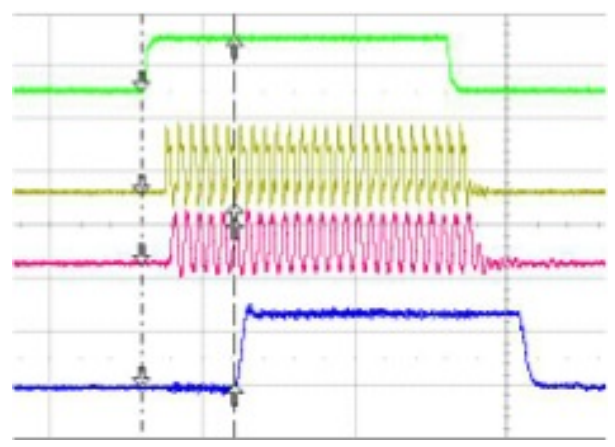

Figure 14: Oscilloscope plot showing from top to bottom: input PWM signal (500 kHz, 50\% duty-cycle), Modulated signal trough transformer $(12 \mathrm{MHz})$, recovered data signal at the receiver's output and gate voltage output.

Conclusion. The coreless transformers are compatible with the X-Relsemi circuits.

\subsubsection{Coreless transformers at $200^{\circ} \mathrm{C}$}

In a previous paper, [13] endurance tests on the coreless chip had been performed at $200^{\circ} \mathrm{C}$ and an important degradation was observed. It was caused by oxydation of the insulation layer as no specific coating was used. In recent tests, the coreless chips have been coated with Parylene and the preliminary results are presented in figure 15. The parameter used to es-

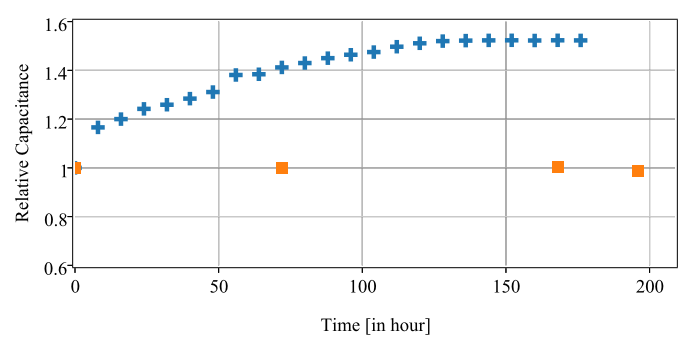

Figure 15: Relative capacitance evolution with in blue, the preliminary endurance test without Parylene, in orange the test with coated Parylene. The measurement error is estimated to be less than 5\%, which corresponds to the height of the symbols used in the diagram.

timate the ageing is the parasitic capacitance between the primary and the secondary windings of the coreless 
transformer. It can be observed that for coated transformer, there is no significant degradation.

A preliminary conclusion is that the proposed coreless transformers withstand a temperature of $200^{\circ} \mathrm{C}$.

\section{First experimental results of the power module with the gate driver and power supply}

The GaN HEMT power module is connected to the gate driver powered by the flyback converter with post regulation. At the time of writing, the module has not been tested on the full stated power range (200V, 20A) partly because of packaging issues and also because we are experimenting on a single sample. We have used a derating of $40 \%$ for the switched current (12A) to circumvent a thermal path flaw in the experimental package. The voltage derating is $70 \%$ to take into account overshoots. This value is acceptable in comparison to industrial deratings in the order of $50 \%$ to $60 \%$ for commercial power switching components.

The first experimental results validate the system functions and shows some limits of the power module packaging. Figures 17 and 18 display some of the switching behavior of the module. Ringing is visible producing a voltage overshoot unto $80 \mathrm{~V}$. Figure 17 shows the ability of the module to switch $12 \mathrm{~A}$.

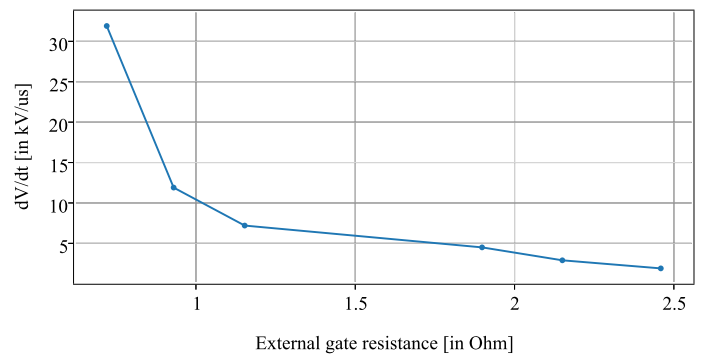

Figure 16: External gate resistance driver impact on $d V / d t$ (Vbus=60 V Id=1 A).

Because the HEMT is a charge controlled device, that is, the driver must supply the gate a fixed quantity of electric charge in order to bias the device, the gate resistor impacts the switching speed. This effect is plotted in figure 16. A maximum $2.4 \mathrm{kV} / \mathrm{us}$ $d V / d t$ was observed during this test. It is very to low to what was expected (around $38 \mathrm{kV} / \mathrm{us}$ [11]), this explains by the not optimized packaging of the GaN inverter leg that impacts particularly the gate inductance and the built-in gate resistor of the driver (1.2 Ohms).
At the time of writing, generation 2 of GaN HEMT are produced and a new package is being designed.

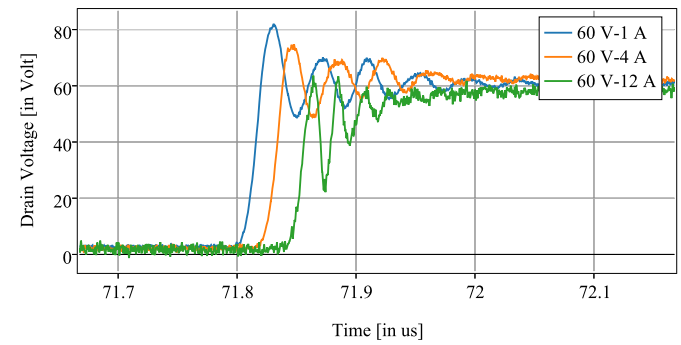

Figure 17: Turn-Off. Drain voltage for different switched drain current values $(\mathrm{Rg}=1.8 \mathrm{Ohms})$.

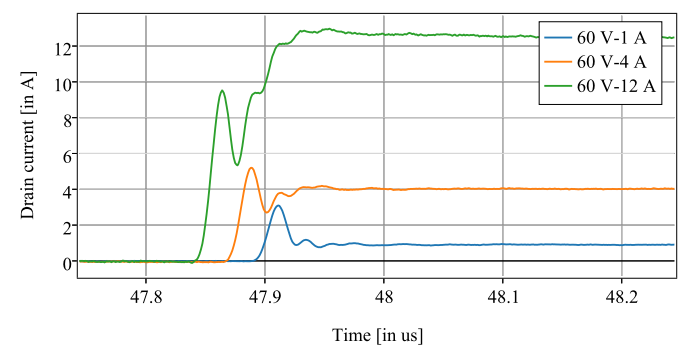

Figure 18: Turn-On. Drain current and different switched drain current values $(R g=1.8 \mathrm{Ohms})$.

\section{Conclusion}

This paper presents a functional GaN power inverterleg module driven by a specific high temperature gate driver with signal and power insulation. Packaging materials and active components are selected and tested to work up to $200{ }^{\circ} \mathrm{C}$. The signal insulation was realized using a coreless transformer and gives good results. It is further pointed out that, due to the large stray inductances from the power terminals and from the gate terminals the expected switching speed was not met. This paper is thought to stimulate further experiments and serve as a start study for GaN high temperature power applications.

\section{Acknowledgments}

This paper is supported by the MeGaN project (French government founded PSPC project for a GaN Electronic Module, named "MEGaN", approved by 
MOVEO and MINALOGIC innovation centers). The acknowledgements would not be complete without a particular attention to the academic engineering and technical support from Pascal Bevilacqua and Abder Zaoui from Ampere-lab. The prototypes would have not been possible without the contribution of $\mathrm{X}$ Relsemi for the supply of engineering samples. The coreless transformers used for the prototypes where produced within the European THOR. (THOR : a European founded project within the CATRENE frame, supported by Euripides, THOR stands for "Striking Technologies for Power"). May Nicolas Quentin and Sébastien Larousse, PhD students at Ampere Laboratory, find here my sympathy for their direct and indirect support to this work.

\section{References}

[1] Ying Y. Device Selection Criteria-Based on Loss Modeling and Figure of Merit. PhD thesis, Electrical and Computer Engineering Virginia Tech, 2008.

[2] Stephen L. Colino and Roberts A. Beach. Fundamentals of galium nitride power transistors. epc-co.com, 2009.

[3] Roberts J. Integrated gan power modules, gan systems inc. HITEN, 2013.

[4] Tim McDonald. Ir's ganpowir and the inherent performance advantages of gan-based hemts. APEC, 2012.

[5] F. Dubois, D. Bergogne, D. Risaletto, R. Perrin, A. Zaoui, H. Morel, and R. Meuret. Ultrafast safety system to turn-off normally on sic jfets. pages 1-10, Aug 2011.

[6] D. Bergogne, H. Morel, D. Planson, D. Tournier, P. Bevilacqua, B. Allard, R. Meuret, S. Vieillard, S. Raël, and F. Meibody-Tabar. Towards an airborne high temperature sic inverter. In Power Electronics Specialists Conference, 2008. PESC 2008. IEEE, pages 3178-3183, June 2008.

[7] F. Dubois, S. Sorel, S. Dhokkar, R. Meuret, D. Bergogne, C. Martin, B. Allard, H. Morel, and R. Wang. A high temperature ultrafast isolated converter to turn-off normally-on sic jfets. In Energy Conversion Congress and Exposition (ECCE), 2012 IEEE, pages 3581-3588, Sept 2012.

[8] Khalil El Falahi, Fabien Dubois, Dominique Bergogne, Luong Viet Phung, Cyril Buttay, and Bruno Allard. High temperature anti short circuit function for normally-on SiC JFET in an inverter leg configuration. In Proceedings of the IMAPS International Conference and Exhibition on High Temperature Electronics, page 6p, Albuquerque, États-Unis, May 2012.

[9] Dominique Bergogne, Fabien Dubois, Christian Martin, Khalil El Falahi, Luong Viet Phung, Cyril Buttay, Sonia Dhokkar, Bruno Allard, Régis Meuret, and Hervé Morel. An Airborne High Temperature SiC Power Converter for Medium Power Smart Electro Mechanical Actuators. In IMAPS, editor, Proceedings of the IMAPS International Conference and Exhibition on High Temperature Electronics, page 6p, Albuquerque, États-Unis, May 2012.

[10] Damien Risaletto, Dominique Bergogne, Fabien Dubois, Hervé Morel, Bruno Allard, and Régis Meuret. A $200^{\circ} \mathrm{c}$ safety system at power-up of normally-on sic jfets inverters. 2013.

[11] M. Rodriguez, G. Stahl, D. Costinett, and D. Maksimovic. Simulation and characterization of gan hemt in high-frequency switched-mode power converters. In Control and Modeling for Power Electronics (COMPEL), 2012 IEEE 13th Workshop on, pages 1-6, June 2012.

[12] Shu Ji, D. Reusch, and F.C. Lee. High frequency high power density $3 \mathrm{~d}$ integrated gallium nitride based point of load module. In Energy Conversion Congress and Exposition (ECCE), 2012 IEEE, pages 4267-4273, Sept 2012.

[13] D. Bergogne, C. Martin, P. Bevilacqua, W. Zine, J.-C. Riou, H. Izzeddine, R. Meuret, and B. Allard. Integrated coreless transformer for high temperatures design and evaluation. In Power Electronics and Applications (EPE), 2013 15th European Conference on, pages 1-8, Sept 2013.

[14] D. Costinett, Hien Nguyen, R. Zane, and D. Maksimovic. Gan-fet based dual active bridge dc-dc converter. pages 1425-1432, March 2011.

[15] H. Umegami, Y. Nozaki, M. Yamamoto, and O. Machida. A novel high efficiency gate drive circuit for normally off type gan-fet. In Energy Conversion Congress and Exposition (ECCE), 2012 IEEE, pages 2954-2960, Sept 2012.

[16] Xiucheng Huang, Qiang Li, Zhengyang Liu, and F.C. Lee. Analytical loss model of high voltage gan hemt in cascode configuration. Power Electronics, IEEE Transactions on, 29(5):2208-2219, May 2014.

[17] Christian Martin, Rémi Robutel, Cyril Buttay, Fabien Sixdenier, Pascal Bevilacqua, Hervé Morel, and Régis Meuret. High Temperature Ageing of Fe-based Nanocrystalline Ribbons. page 6p, May 2012.

[18] Umesh K. Mishra, Primit Parikh, and Yi-Feng Wu. Algan/gan hemts-an overview of device operation and applications. Proceedings of the IEEE, 90(6):1022-1031, Jun 2002.

[19] Rémi Robutel, Christian Martin, Hervé Morel, Cyril Buttay, Nicolas Gazel, and Dominique Bergogne. Design of a High Temperature EMI Input Filter for a 2 kW HVDC-Fed Inverter. Journal of Microelectronics and Electronic Packaging, 8(1):23-30, 2011.

[20] Fabien Dubois, Dominique Bergogne, Damien Risaletto, Rémi Robutel, Hervé Morel, Régis Meuret, and Sonia Dhokkar. High Temperature Inverter for Airborne Application. In Proceedings 2010 IMAPS International Conference and Exhibition on High Temperature Electronics, page 000222, Albuquerque, États-Unis, May 2010. 